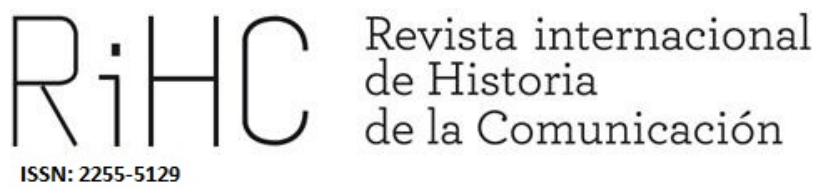

\title{
PRENSA DE MODA PARA HOMBRES EN ESPAÑA: INTERESES DE CLASE Y TENDENCIAS EN LA GUÍA DEL PELUQUERO (1873-1880)
}

\section{Fashion press for men in Spain: association and trends in the Guía del peluquero (1873-1880)}

DOI: http://dx.doi.org/10.12795/RiHC.2018.i10.03

aceptado: $28 / 03 / 2018$

recibido: $21 / 04 / 2018$

publicado: $25 / 05 / 2018$

Ana María Velasco Molpeceres (D) https://orcid.org/0000-0002-0593-0325

Universidad de Valladolid, anamariavelascomolpeceres@gmail.com

Resumen: El objetivo es investigar sobre las primeras publicaciones especializadas en moda en España y, en concreto, acerca de la Guía del peluquero (1873-1880). Esta cabecera es interesante porque es de las pocas que trataban temas de moda para el público masculino, aunque el tema predominante era la moda femenina, especialmente en peinados. Así recoge un valioso testimonio sobre las costumbres de la España de finales del XIX, para ambos sexos. Además, representa una excepción dentro de la prensa de moda porque pretendía ser un medio de defensa de los intereses de la clase obrera y 
también un vehículo educativo, de la profesión y del mundo. Se trata, pues, de un órgano proto sindical, en sintonía con el movimiento obrero del momento. Su existencia nos habla de un acercamiento de la prensa a los trabajadores y, por tanto, de la mayor alfabetización, capacidad de consumo y desarrollo. Su larga vida prueba su trascendencia. Para su estudio hemos utilizado la Ficha hemerográfica diseñada por Celso Almuiña.

Palabras clave: moda, prensa de moda, cabello, España, movimiento obrero

\begin{abstract}
This article studies one of the first specialized publications in fashion in Spain: the Guía del peluquero (1873-1880). This magazine is interesting because it is one of the few that dealt with topics of fashion for the male audience, although it also included content for women. It reveals the uses and customs of the Spanish people at the end of the XIX century, for both sexes. In addition, it represents an exception in the fashion press because it defends the interests of the working class and also it was an educational vehicle. It is, therefore, a proto-union organ, in tune with the labour movement. The existence of the magazine reflects the approach to the workers in Spain and the rise of the life level. The long life of the Guía proves the transcendence. For its study we have used the analysis sheet designed by Celso Almuiña, Professor of Contemporary History at Universidad of Valladolid (Spain).
\end{abstract}

Keywords: fashion, fashion press, hair, Spain, labour movement

\title{
Introducción
}

El objetivo de este trabajo es investigar sobre las primeras publicaciones especializadas en moda en España y, en concreto, acerca de la Guía del peluquero (1873-1880). Esta cabecera es interesante porque es de las pocas que trataban temas de moda para el público masculino, aunque el tema predominante era la moda femenina, especialmente en peinados. Además, recoge un valioso testimonio sobre las costumbres de cuidado personal, higiene y belleza de la España de finales del XIX, un tema desatendido en general por las publicaciones de moda y los historiadores.

Igualmente, representa una excepción dentro de la prensa de moda y las tendencias porque, además de recoger las novedades, pretendía ser un medio de defensa de los intereses de la clase obrera. Se trata, pues, de un órgano proto sindical, en sintonía con el movimiento obrero del momento. Su existencia nos habla de un acercamiento de la prensa a un público trabajador y, por tanto, de la mayor alfabetización, capacidad de consumo y desarrollo social del momento. Su larga vida es prueba de lo mencionado, así como de su trascendencia.

La prensa de moda en España surgió con dificultad a principios del siglo XIX. El periódico El amigo de las Damas (1813) es el introductor del género en el país, aunque el regreso de Fernando VII acabó con los logros liberales y la libertad de prensa fue férreamente 
controlada. Durante el breve trienio constitucional aparece El Periódico de las Damas (1822) que dada la vuelta del absolutismo poco después tampoco logró sobrevivir. Llama la atención que, apareciendo los figurines (de origen francés, además) por primera vez, el del primer número aluda a la moda masculina, pese a ser la cabecera indudablemente para mujeres. Posteriormente se incluirán imágenes y noticias en otros medios femeninos que se refieren a la moda masculina pero son casos excepcionales.

Desde la muerte de Fernando VII los periódicos para mujeres que tratan sobre moda se suceden. El Correo de las Damas (1833-1835) surgió en la agonía del soberano y se extendió unos cuantos años más, siendo protegido por la regente y también por la reina niña. La introducción de las modas francesas frente a las españolas fue un tema de gran calado en la publicación, y en la época, constatándose en el siglo XIX la pérdida de prestigio de la vestimenta a la española y el aprecio a los modelos franceses que van a ser difundidos por las revistas de moda. El reinado de Isabel II consolida las publicaciones femeninas y aparecen numerosas de ellas, contando muchas con la suscripción de la soberana. No obstante, los problemas de supervivencia a lo largo del tiempo son numerosos pues no consiguen encontrar un grupo de lectores que hagan que se mantengan.

Pese a esto hubo varias cabeceras de gran trascendencia y longevidad como La Moda Elegante (1842-1927) o El Correo de La Moda (1851-1893); otras de importante repercusión como Ellas (1851-1853), La Educanda (1861-1865), La Violeta (1862-1866), El Ángel del Hogar (1864-1869), La Guirnalda (1867-1883), etc. además de decenas de títulos que fueron sucediéndose con diferente suerte. Y tras la Gloriosa, con la llegada de un nuevo modelo comunicativo democrático, frente al más controlado del reinado de Isabel II, que decreta la libertad de prensa desde el Gobierno Provisional de Sagasta de octubre de 1868 y lo refrenda en la Constitución de 1869, se desarrolla aún más la prensa y también la dedicada a la moda.

Es en ese contexto, el del Sexenio Democrático (1868-1874), cuando aparece la Guía del Peluquero (1873-1880) que es una publicación al tiempo de moda y también de clase, relacionada con los intereses del gremio de peluqueros y barberos, pero cuyo público objetivo son los varones. Esto hace que sea una excepción en la historia de la prensa de moda y un valioso testimonio de, entre otras cuestiones, el peinado y la historia de la peluquería en España. 


\section{Estado de la cuestión: moda y prensa}

El estudio de la historia de los medios de comunicación viene de lejos y hay numerosos investigadores que se han dedicado a ello con enorme interés. Por otra parte, los trabajos dedicados a investigar el origen de la prensa de moda y su dimensión histórica no son tan numerosos, aunque la importancia de estas publicaciones en todo el mundo fue destacada. Es por ello que este trabajo pretende llenar un hueco historiográfico y continuar los estudios sobre este tipo de medios.

Tradicionalmente se considera que el Mercure Galant (1672-1724), en la Francia de Luis $\mathrm{XIV}$, fue el primer periódico que se hizo eco de las noticias de la corte para mantener a la sociedad elegante a tono con las tendencias imperantes en el complejo ambiente barroco de Versalles. Con el rey Sol fue también el momento en que la moda surgió en buena medida como se entenderá la contemporaneidad. Sin embargo, hay una diferencia fundamental con el escenario posterior a la Revolución Francesa pues aquí la moda y el lujo no están asociados a lo femenino, sino que son temas de interés para ambos sexos. Tras 1789, cuando los hombres (como estudió Flügel) adopten el traje de tres piezas hasta hoy y sean las mujeres las que conviertan el vestir en un arte, un medio de expresión y una dimensión que desafía y mantiene el ideal de domesticidad que se extiende en la sociedad liberal, la moda va a ser vista como un espacio de la mujer.

Es por eso que a menudo, y en consonancia con la visión de la época, desde finales del siglo XVIII y sobre todo en el XIX la moda y la prensa que refleja las tendencias va a tildarse de femenina $y$, en general, va a dirigirse a la mujer. Por ello la mayoría de estudiosos que tratan el tema van a incluir la prensa de moda en la prensa femenina. La historia de este tipo de medios en los diferentes países ha sido investigada con diferentes enfoques. Cabe destacar los trabajos de Pippa Norris (1997) acerca de las mujeres, los medios y la política, los de Mary Ellen Zuckermann (1998) sobre la prensa femenina en Estados Unidos (desde el siglo XVIII a finales del XX), los de Nancy Walker (1998) indagando en los roles femeninos transmitidos por esta prensa a mediados del siglo XX o los de Anna Gough-Yates (2003) sobre la historia de la prensa para mujeres.

En España quizá los trabajos más interesantes sean los de Inmaculada Jiménez Morell para el siglo XIX (1992), los de María del Carmen Simón Palmer (1975, 1991, 1993 y 2014) y la ingente obra de Jean François Botrel (1993 y 2003). Cabe destacar la labor de Juana Gallego (1990 y 2013) que no solo ha estudiado la historia de la prensa femenina sino el papel de motor o rémora del feminismo de la misma. También es reseñable la obra de María Garrido (2012) que habla del vacío en la investigación pues señala que las revistas femeninas han vivido un desdén y la tesis de Carmen Muñoz (2002) sobre la prensa para mujeres en la España de mediados de siglo XX. Los trabajos de Adolfo Perinat y María Isabel Marrades (1980), así como los de María Sánchez Hernández (2009) y Mercedes Roig (1977 y 1989), son claves para conocer la relación entre prensa y sociedad y la evolución de las revistas femeninas. Y por supuesto la obra que apadrina el resto de 
estudios sobre prensa es posible que sea la de Eugenio Hartzenbusch (1894) sobre los periódicos madrileños de la Biblioteca Nacional de España.

No obstante, como hemos mencionado, es un tipo de prensa poco estudiado, tanto agrupada dentro de la femenina como por sí sola. Su relación con la indumentaria y sus cambios hace que a menudo sea acusada de frívola o de poco interesante, en sintonía con la opinión sobre la moda y sus dimensiones sociales, por lo que durante mucho tiempo no ha sido objeto de interés para la mayoría de investigadores. Los historiadores de la moda y del traje, destacando a Max von Boehn (1928) o James Laver (2006), desatienden estas publicaciones y su historia y se centran en los cambios de las prendas a través de ellas o del arte. En la mayoría de compilaciones sobre la historia de la prensa apenas se dedica unas líneas a estas publicaciones, sobre todo en el siglo XVIII y XIX, pero tampoco reciben mucha más atención en los trabajos de historia de la moda.

Otro campo que ha quedado desatendido por los investigadores es la historia del peinado. Cabe destacar el trabajo de Erika Bornay (1994) o la investigación de Luigi Amara (2014) sobre las pelucas. También son interesantes las obras clásicas de Garsault sobre el Arte de Barbero-Peluquero-Bañero... que fue traducido por García Santos en 1771, la memoria sobre peinadores de Madrid de Lorenzo de Isisarri (1780) o las ordenanzas del gremio de peluqueros de Carlos III (1791). También la historia de las pelucas del Dr. Arkelio Rapsodia traducida en español en 1806, el manual de peinado para mujeres y peluqueros de M. Villaret (1832), el manual instructivo para el barbero de pueblo de Vicente Gay Taenga (1877) o la historia del peinado (1880) de Francisco Barado. Otra fuente interesante es, precisamente, la revista Guía del peluquero (18731880) que pretendemos estudiar en este artículo.

Esta publicación es por tanto una obra importante a la que acercarse permite conocer tanto aspectos de la historia de la prensa, como de la moda y del peinado en España en el siglo XIX pero también del asociacionismo pues la publicación era un órgano creado para defender los intereses de clase de los peluqueros y barberos. Su destinatario era precisamente ese gremio por lo que este periódico representa una excepción en la prensa de moda del período pues se orientaba a hombres y no a mujeres, aunque parte del contenido era sobre tendencias femeninas. En el siguiente epígrafe explicaremos cómo hemos estudiado la cabecera. 


\section{Metodología}

Este análisis se hace partiendo de la ficha hemerográfica propuesta por el profesor Celso Almuiña en su Tesis Doctoral (1977) pero reinterpretándola según nuestras necesidades, como el propio autor hace en sus publicaciones. La ficha permite analizar las características básicas de cada cabecera así como los aspectos empresariales y redaccionales de la misma. Además contempla la dimensión histórica de la publicación, el contexto en el que se inscribía y la importancia de la misma en el momento de su edición. Igualmente incluye un análisis de contenido del medio, indagando en la vida de la cabecera. Por todo ello resulta un completo y actual modo de estudio para la prensa, especialmente para los títulos históricos.

La ficha hemerográfica es como sigue:

I. Ficha descriptiva
A) Cabecera:
1. Título:
2. Subtítulo:
3. Lemas:
B) Datación:
1. Cronología:
a) Primer número:
b) Último número:
c) Suspensiones:
2. Periodicidad:
3. Geodifusión:
C) Características técnicas:

1. Formato:
a) Páginas:
b) Dimensiones:
c) Columnas:

2. Estructura:

a) Secciones:

3. Impresión:

II. Ficha analítica
a) Impresor:

D) Empresa:

1) Aspectos jurídicos:

a) Fundadores:

b) Propiedad:

2) Aspectos económicos:

a) Administración:

b) Precio:

a') Venta al número:

b') Suscripción:

c) Publicidad:

E) Equipo redaccional: 
1) Dirección:

a) Consejo de Redacción:

b) Director:

2) Redacción:

a) Redactor jefe:

b) Redactores:

3) Colaboradores:

F) Naturaleza y orientación:

G) Difusión:

III. Aspectos históricos

1) Significación:

2) Fuente histórica:

3) Localización de fondos:

IV. Observaciones

V. Estudio de la publicación

\subsection{Ficha descriptiva}

\section{A) Cabecera}

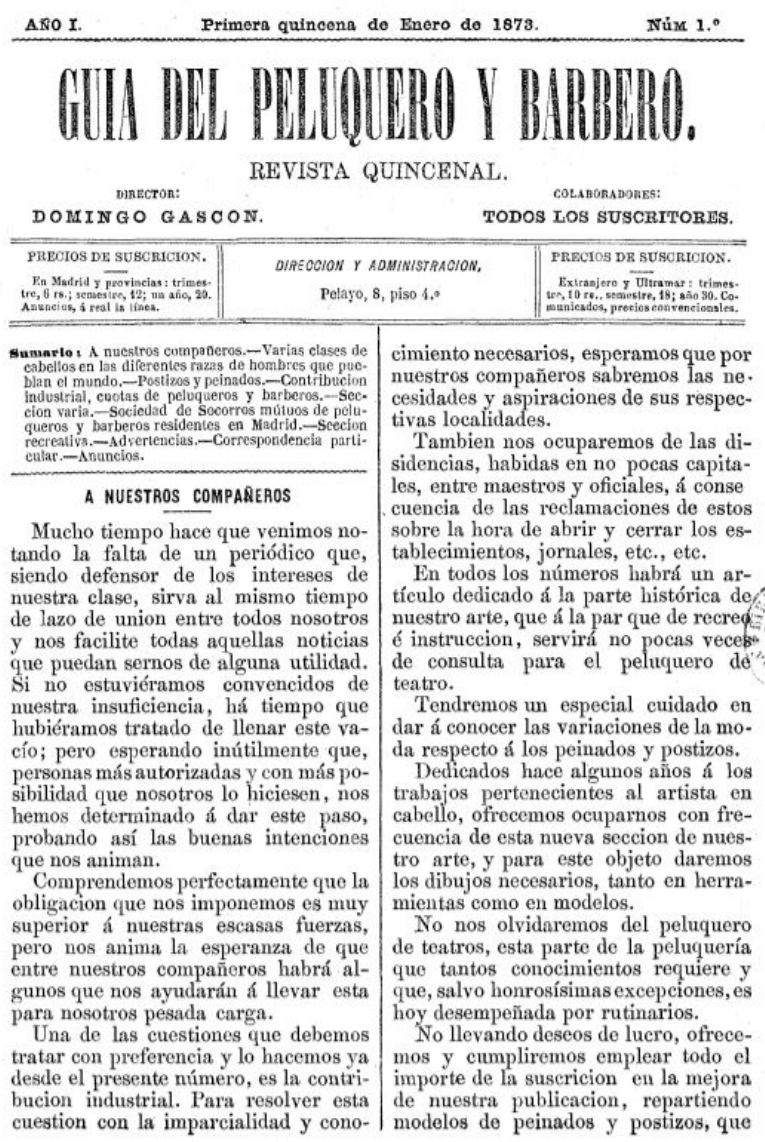


El título de la cabecera en su primer número, del uno de enero de 1873, era Guía del peluquero y barbero. No llevaba subtítulo, informando únicamente de que era una revista quincenal. Cabe mencionar que en los tomos que abren la colección encuadernada se señala en el que engloba el primer año que está "dedicada exclusivamente á defender los intereses y procurar el progreso de la clase que representa". Ese lema también se repite en el tomo del año II aunque el subtítulo de revista quincenal pasa a ser mensual a partir de marzo de 1874, en el número 30.

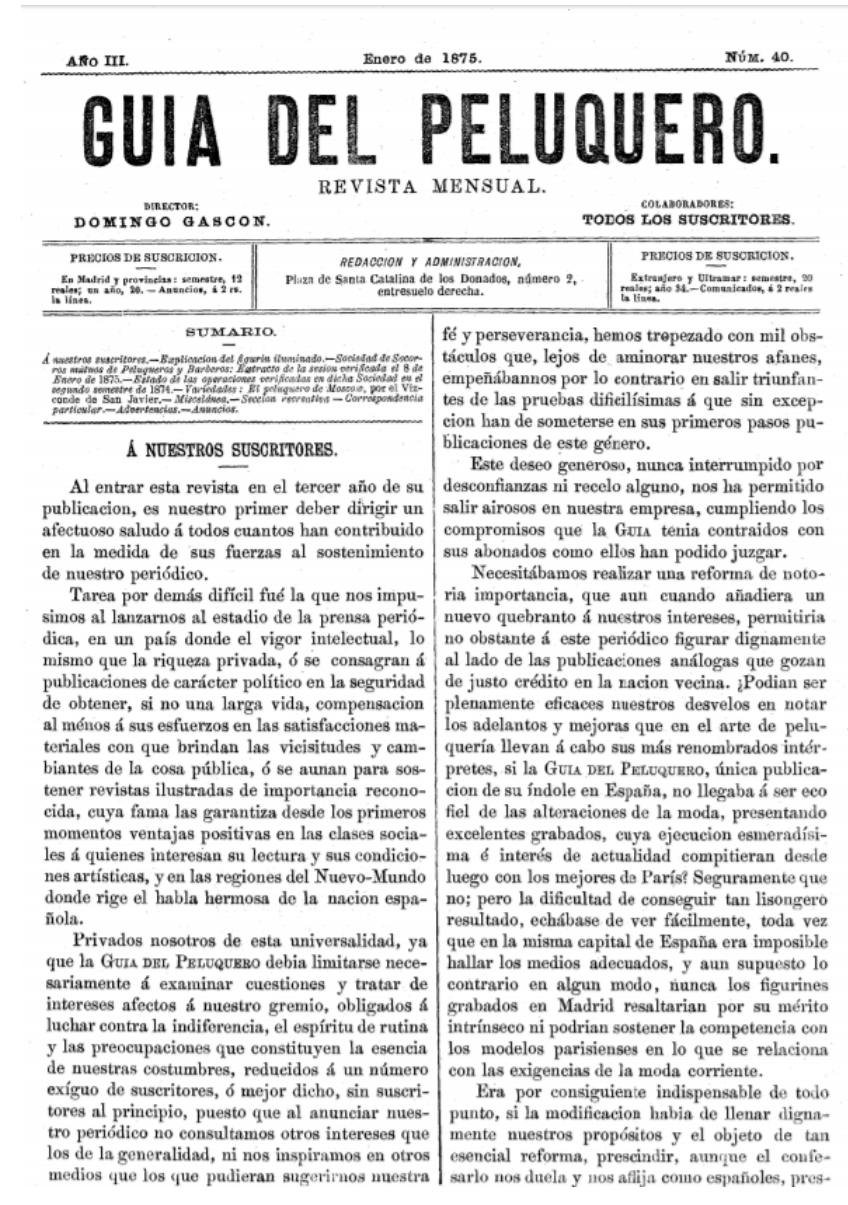

Portada del número cuarenta (enero de 1875) de la Guía del peluquero

A partir de enero de 1875, del número 40, el título de la cabecera pasa a ser solo Guía del peluquero. Durante los años III, IV, V y VI la titulación se mantiene idéntica, aunque en el número 75 de diciembre de 1877 se incluye como subtítulo la frase de la defensa de los intereses de su clase, que no vuelve a aparecer más. En ese número también hay unas páginas extras de anuncios. 


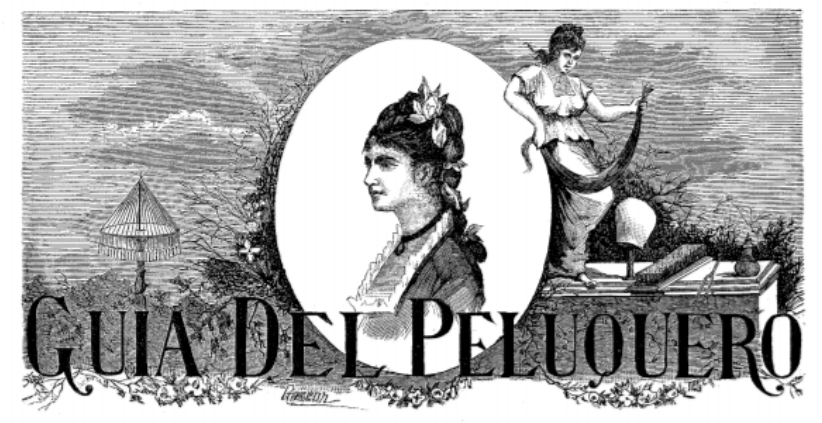

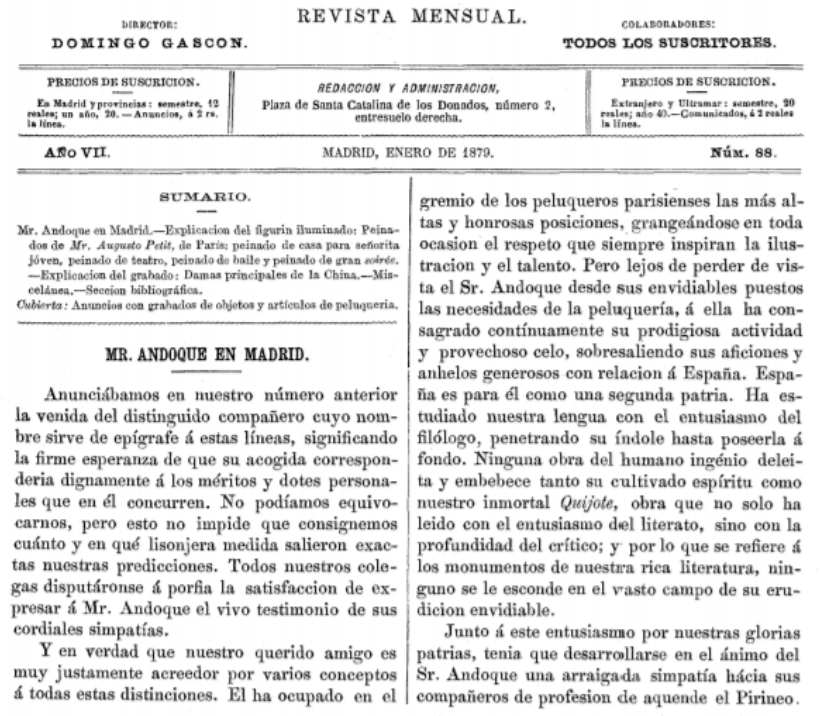

Portada del número ochenta y ocho (enero de 1879) de la Guía del peluquero

A partir del año VII y del número 88 , de enero de 1879 , se incorpora a la cabecera la imagen grabada de una dama con un hermoso peinado que va enmarcada en un medallón, a cuyo lado hay una mujer vestida al modo clásico que sujeta un largo mechón de pelo. También aparece un pequeño bodegón de objetos de peluquería y abajo del todo, discretamente, aparece la firma de Gascón que era el director y creador de la revista y al que parece plausible atribuir el diseño de la imagen. 


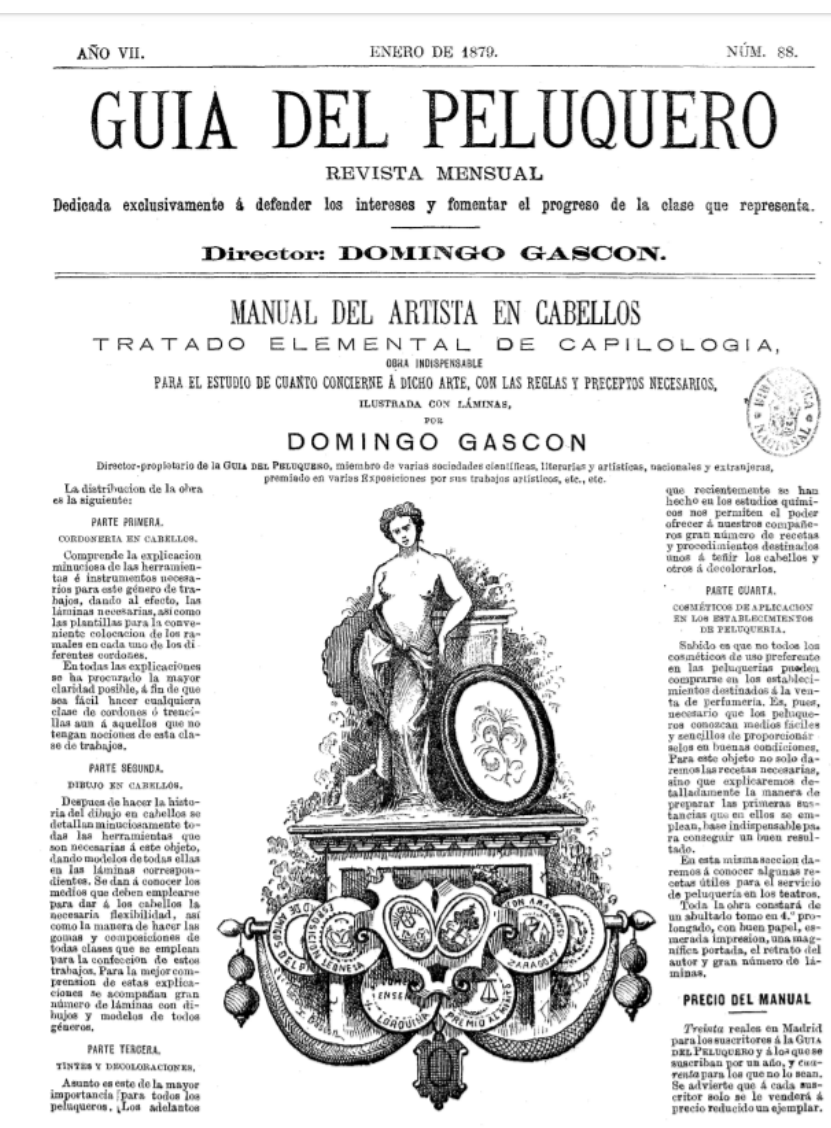

Portada del suplemento publicitario, editado desde el número ochenta y ocho, con la Guía

Además desde ese número y hasta el último, el 108 de septiembre de 1880, (salvo en los números 93 y 97) se incluye una especie de suplemento, con publicidad y otra información, que lleva el mismo título que la publicación principal (Guía del peluquero) y subtítulo (Revista mensual Dedicada á defender los intereses y fomentar el progreso de la clase que representa) pero que además incluye su propio título y subtítulo: Manual del artista en cabellos, tratado elemental de capilología, obra indispensable para el estudio de cuanto concierne á dicho arte, con las reglas y preceptos necesarios, ilustrada con láminas, por Domingo Gascón, pues el objetivo de las páginas que preceden o anteceden a la revista es fundamentalmente vender ese manual.

\section{B) Datación}

1. Cronología

El primer número de Guía del peluquero lleva fecha, sin especificar, de la primera quincena de enero de 1873 y el último es el 108, de septiembre de 1880 . Parece probable que la revista se editara a finales de diciembre de 1872 o incluso los primeros días del año siguiente.

2. Periodicidad 
La revista tuvo una periodicidad quincenal desde el número uno, de enero de 1873, hasta el 29 de la segunda quincena de febrero de 1874. Desde el número 30, de marzo de 1874 , la periodicidad es mensual.

\section{Geodifusión}

Desde el primer número se dan precios para los suscriptores de Madrid y del resto de provincias, así como para el extranjero e incluso ultramar.

\section{C) Características técnicas}

La revista tiene diferente extensión y no sigue un patrón regular. Lo más habitual es que tengan doce páginas ${ }^{1}$, con ocho de texto y dos figurines con sus correspondientes folios blancos. También hay ejemplares que solo tienen ocho páginas de texto ${ }^{2}$, sin imágenes incluidas y otros que a esas ocho hojas les suman una lámina y su folio blanco ${ }^{3}$. En los últimos años de la publicación aparecen números, de diferente paginación, con un suplemento de publicidad ${ }^{4}$. También hay ejemplares con menor número de páginas de las ocho habituales de texto aunque no son muchos $^{5}$ e incluso hay algún número con mayor extensión ${ }^{6}$.

En todos los ejemplares de la revista el texto va a dos columnas aunque, en raras ocasiones, aparece un título a una columna y a veces el texto de la sección o el anuncio va a dos columnas o incluso a una también. Eso es lo que ocurre por ejemplo en el número 15 , en la sección de la página siete aunque el resto de la página es a dos columnas. A veces aparecen tablas a toda página, como en los números $12,13,14,15$, $25,40,44,49,52,56,63,64,70$ o 82 . También en algunos números hay anuncios que

\footnotetext{
${ }^{1}$ Los números $1,2,3,4,5,6,9,12,16,17$ y 33.

${ }^{2}$ Los números $7,8,10,11,18,19,20,21,22,23,25,26,27,28,29$ y 30.

${ }^{3}$ Los números $31,32,34,35,36,37,38,40,41,42,43,44,45,46,47,48,49,50,52,53,54,55,56,57,58$, $59,60,62,64,65,66,67,68,69,70,71,72,73,74,76,77,78,79,80,81,82,83,84,85,86,93$ у 97.

${ }^{4}$ Los números 75, 88, 89, 90, 91, 92, 94, 95, 96, 98, 99, 100, 101, 102, 103, 104, 105, 106, 107 y 108 tienen ese suplemento, que en general tiene cuatro páginas, pero a veces llega a seis u ocho. Hay que señalar que estos ejemplares tienen diferente extensión cada uno. El número 75 tiene seis páginas de texto, un figurín, un folio y un suplemento de publicidad de dos páginas. Los números $88,89,90,91,92,94,95,96$, 98, 100, 101, 102, 103, 105, 106107 y 108 tienen ocho páginas de texto, un figurín y su correspondiente folio en blanco. El 99 tiene nueve de texto, un figurín y un folio blanco. El 104 está encuadernado con dos páginas del suplemento por delante del número y por detrás tiene cinco más y por ello es difícil saber cuáles eran del número regular y cuáles del extra porque la numeración es corrida; en todo caso, descontando las siete de publicidad, tiene nueve de texto, un figurín y un folio blanco.

${ }^{5}$ El número 24 tiene seis páginas de texto, dos láminas y dos folios blancos. El número 39 tiene siete páginas de texto, tres láminas y un folio blanco. El 51 y el 87 tiene siete páginas de texto, una lámina y un folio blanco.

${ }^{6}$ El 61 tiene doce de texto, un figurín y una hoja blanca. El 63 y el 75 tienen trece páginas, de las que once páginas son de texto y además hay un figurín y un folio.
} 
ocupan toda la hoja y que no llevan texto en columnas, por ejemplo en los ejemplares $19,20,21,22,23,25,58,59,60,102,103,104,105,106,107$ у 108.

Los grabados que aparecen en la revista siempre son en blanco y negro y en general se entregan figurines iluminados. Cabe mencionar que la publicidad incluye numerosas imágenes, sobre todo de productos específicos del gremio que están a la venta. La apariencia de la revista no destaca por su diseño peculiar pero sí que están cuidadas las imágenes que se incluyen. La composición aún recuerda al formato libro, aunque a medida que va incorporando imágenes pierde ese aspecto.

\section{Estructura:}

El esquema de la publicación varía según los diferentes números. La paginación cambia, las secciones tampoco se mantienen y a veces se incluye un suplemento con publicidad o figurines iluminados, que van aparte. En general las secciones incluyen una nota a los lectores, artículos sobre la historia del gremio de peluqueros o acerca de algún aspecto relacionado con el peinado, el pelo o la barba, explicaciones del figurín, información sobre la Sociedad de Socorros mutuos de peluqueros y barberos, anuncios y correspondencia particular e información de peinados y tendencias del momento, así como de las novedades de París. En ocasiones se incluye una sección de variedades, que pretende ser recreativa, y también cuestiones relacionadas con la profesión en diferentes provincias remitidas por distintos trabajadores. También aparecen a veces composiciones literarias, relacionadas con la peluquería.

3. Impresión:

Desde el primer al último número, de 1873 a 1880, la imprenta es la de Pedro Núñez pero primero se denomina "Imprenta de P. Núñez" y se sitúa en Madrid en la Corredera Baja de San Pablo, 43. Luego, en el número 67 de abril de 1877, se da cuenta de que se imprime en el "Establecimiento tipográfico de Pedro Núñez", situado en la calle de la Palma Alta, número 32.

\subsection{Ficha analítica}

\section{D) Empresa:}

1) Aspectos jurídicos:

a) Fundadores y propiedad:

La Guía está asociada a la Sociedad de Socorros mutuos de peluqueros y barberos por lo que este grupo tiene relación con su fundación, pues la cabecera es un órgano de la misma. Sin embargo, su principal ideólogo es Domingo Gascón, que será su director y su propietario. 
2) Aspectos económicos:

a) Administración:

La dirección y administración de la Guía estuvo entre enero de 1873 y junio de ese año en la calle Pelayo, número 8 , piso 4 을 de Madrid. Luego, desde el número doce, pasó a la calle Peligros ( $n$ o 10 y 12). El último cambio es en el número dieciocho, en septiembre de 1873, cuando la dirección es Plaza de Santa Catalina de los Donados, número dos, entresuelo derecha.

Las suscripciones podían hacerse en la administración, e incluso con los números repartieron papeletas para suscribirse a domicilio (en Madrid, a través del repartidor y en provincias por un giro o en sellos). Igualmente era posible hacerlo en las poblaciones donde la Guía tenía un corresponsal ${ }^{7}$ del gremio de la peluquería. Durante toda la vida de la cabecera la preocupación por hacer nuevas suscripciones y cobrar las cuotas de los asociados ocupa importante espacio con el objetivo de asegurar la viabilidad de la revista.

b) Precio:

En el primer número se establece que en Madrid y provincias el precio de la suscripción al trimestre es de seis reales, al semestre es de doce y al año es de veinte. En extranjero y ultramar el trimestre cuesta diez reales, el semestre dieciocho y el año treinta. También se señala que los anuncios son a un real la línea y que los precios de comunicados son a precios convencionales. En el número treinta y uno, de abril de 1874 , cambia el precio de la suscripción en el extranjero y en ultramar que pasa a ser de veinte reales el semestre y de treinta y cuatro al año. Además se dice que los anuncios pasan a costar dos reales y los comunicados esa misma cifra la línea. Este será el precio que se mantenga hasta el final de la cabecera.

En el número sesenta y tres, de diciembre de 1876, se informa de que hay a disposición de los interesados algunos tomos encuadernados de la Guía de los tres años anteriores y de que comprando los tres cuestan veinte reales el tomo. Por otra parte, en el número setenta y cinco, de diciembre de 1877, cuando aparece por primera vez una especie de suplemento de publicidad (que no vuelve a repetirse hasta el ochenta y ocho y siguientes) se dice que el precio de la línea de anuncios de esas páginas es de cincuenta

\footnotetext{
${ }^{7}$ En el número uno indican que esos lugares son: Valladolid, Barcelona, Valencia, Zaragoza, en la que se hacía a través de José Gascón, que era hermano del director y colaboró en algún número, Sevilla, Albacete, San Sebastián, Salamanca, Málaga y Huesca. Posteriormente incorporan nuevos municipios: Santander, Tarragona, Cartagena, Requena, Alicante, Coruña, Gijón, Murcia, Cuenca, Vitoria, Pamplona, Burgos, Logroño, Bilbao y, desde el número siete, incluyen Portugal y La Habana. Y la lista aún se amplía tiempo después a Soria, Córdoba, Gerona, Cádiz, pero lo más interesante es que logran tener contactos en las principales capitales internacionales. En febrero de 1879 la revista se puede comprar en Londres, Berlín, Lisboa, París, Bayona, Marsella, Lyon, Roma, Milán, Turín, Bruselas, Fráncfort, San Petersburgo, Alejandría, Campinas, Buenos Aires, Montevideo, La Guaira y Nueva York.
} 
céntimos de peseta, que va a ser el que se mantenga en ese suplemento cuando se edite. También se reseña que la administración se guarda el derecho a aprobar o rechazar la publicidad. Los precios de los anuncios en la revista normal siguen siendo de dos reales la línea y esa cifra va a durar hasta que acabe la publicación.

\section{E) Equipo redaccional:}

1) Dirección:

Domingo Gascón y Guimbao nació en Albarracín en 1845 y falleció de una afección cardiaca el 29 de agosto de 1908 en Carabanchel Bajo. Es conocido como "tercer amante de Teruel", equiparándole a Isidoro de Antillón y Víctor Pruneda, a quienes dedicó una biografía. Estudió en Albarracín, Mora de Rubielos, Zaragoza, Madrid y Valencia y en su juventud trabajó como barbero y peluquero. En la noticia del periódico Las Provincias ${ }^{8}$ que da cuenta de su muerte se dice que vivió en Valencia en su juventud, adonde huyó tras tomar parte del alzamiento federal de 1869. Luego se trasladó a Madrid y se estableció como peluquero en la plaza de Santa Catalina, donde en 1877 se anunciaba como almacenista de cabellos de todas clases y artista en cabellos premiado en diferentes exposiciones.

Presidió la Sociedad de Socorros Mutuos de Peluqueros y Barberos y en ese ambiente fundó y dirigió la publicación Guía del Peluquero y Barbero (1873-1880) en la que, además de relacionar las últimas tendencias tanto masculinas como femeninas, abogó por el cooperacionismo y por la defensa de los intereses de clase. Intentó que el gremio alcanzara repercusión internacional y estableció una potente relación con Francia. En 1881 abandonó la peluquería y pasó a dedicarse al periodismo y a la política, lo que explica el final de la cabecera. En ese período trabajó como corresponsal en Madrid de distintos periódicos como La Derecha (donde dio cuenta de la campaña política republicana que realizó), El Diario de Huesca, La Voz de Galicia o el Diario de Manila y además colaboró en publicaciones como El Turolense, Eco de Teruel, Boletín de Historia y Geografía del Bajo Aragón, Revista Aragonesa, Revista Aragón, Diario de Avisos de Zaragoza y en los diarios madrileños El Progreso y El Liberal.

En 1891 fundó la publicación gratuita Miscelánea Turolense (1891-1901) que daba datos sobre la provincia de Teruel, abogando por el regeneracionismo de la misma, y, un año después de su fundación, y hasta 1895, se convirtió en el Cronista oficial de la provincia. Además en 1895 fue uno de los fundadores de la Asociación de la Prensa de Madrid. Él mismo se definía como un trabajador incansable y, de hecho, ya adulto obtuvo la licenciatura de Derecho y estableció en la capital una Agencia General de Negocios en la que se ofrecía como abogado y colegiado para representar a Diputaciones, Ayuntamientos, Compañías, Sociedades, Corporaciones y particulares. De hecho, representó en Madrid al Ayuntamiento de Zaragoza en distintos asuntos, como el

\footnotetext{
8 “D. Domingo Gascón”, Las Provincias: diario de Valencia, 1-09-1908, nำ15.324, p. 1.
} 
traslado de los restos de Goya a Aragón. En 1898, y hasta 1902, cuando traspasó la dirección a su sobrino, publicó el Boletín Minero y Comercial (1898-1906), órgano de la Agencia General de Minas.

Como candidato del partido republicano no logró un escaño en el Congreso de los Diputados, ni en 1893, ni en 1896; teniendo que esperar a ser elegido por Boltaña para las legislaturas 1901-1902 y 1902-1903, impulsando varias obras públicas. Por otra parte, en torno a esos años, también se dedicó a la adquisición y venta de concesiones para la explotación de minas enclavadas en Teruel. Actividad que compaginó con su labor intelectual, tomando parte de distintas sociedades como las Reales Academias de la Historia y de la Lengua, Círculo Aragonés de Madrid, Sociedad Económica de Teruel, Real Sociedad Económica Matritense, Academia de Jurisprudencia y Legislación, Asociación de Escritores y Artistas, Real Sociedad Aragonesa de Amigos del País y el Ateneo de Madrid.

De su vida personal sus biógrafos destacan su afición por el trabajo. Casado con Manuela Martín Castro, tuvieron dos hijas: Pilar, que falleció prematuramente en 1891, y Consuelo. Entre sus escritos destacan el Manual del artista en cabellos, tratado elemental de capilología (1878); Un viaje por Galicia, Portugal y Andalucía (1886), la biografía de Mariano Nipho y la de Juan Martínez Salafranca (1887), Apuntes para una lista de periodistas aragoneses (1889), la biografía de Juan Lorenzo Palmireno (1905), Cancionero de los Amantes de Teruel (1907), Prelados turolenses por el lugar de su nacimiento (1907), Relación de escritores turolenses (1908) y La provincia de Teruel en la Guerra de la Independencia que apareció póstumamente.

Respecto a la Guía del Peluquero, la personalidad de Gascón impregna toda la publicación. No ejerce solo como director sino también como propietario e ideólogo y, en calidad de miembro y luego presidente de la Sociedad de Socorros Mutuos de Peluqueros y Barberos, es el máximo responsable de este órgano que pretende ejercer como cohesionador del gremio. En la cabecera no se da cuenta de quién compone la redacción, ni hay datos de su redactor jefe, aunque desde luego parece que es Gascón su promotor $y$, atendiendo a las firmas, su principal redactor.

2) Colaboradores:

Pese a que no podemos extraer de la Guía datos sobre la redacción, sí que nos parece importante señalar que desde el primer número en la cabecera se dice que todos los suscriptores son colaboradores y varios de ellos publican en la misma y remiten cartas y contenidos. En general escriben con su nombre completo, incluyendo el rango que tienen en su profesión y el lugar en el que la ejercen. Por ejemplo, en el número tres aparece un artículo de Manuel Santiago, maestro, de Carrera de San Gerónimo, 14, entresuelo, en el que se queja de lo poco que cobran los peluqueros y barberos y llama a la unión del gremio. También es interesante mencionar que aparecen numerosas 
colaboraciones de peluqueros franceses, pues uno de los objetivos del periódico es introducir en el país las modas galas.

\section{F) Naturaleza y orientación:}

Revista de tendencias, órgano de defensa de intereses del gremio de peluqueros y barberos y también de instrucción y recreo.

\section{G) Difusión:}

La publicación se difundió en toda España, pero también debió tener cierta repercusión internacional, centrándose esta sobre todo en Francia y en América Latina.

\subsection{Aspectos históricos}

\section{1) Significación:}

La Guía es una importante publicación dentro de los periódicos sobre moda en España. Se trata de una curiosa excepción porque, en primer lugar, se dirige a un público masculino; en segundo, es una cabecera de tipo profesional y por ello su fin no es entretener sino instruir y velar por la mejora del gremio, difundiendo las novedades internacionales para lograr reconocimiento. Además, incluye mucha información sobre tendencias masculinas, cuando lo normal es que este tipo de productos sean sobre moda femenina, tema que también trata. Por otra parte, la historia del cabello y de la profesión de peluquero es uno de los temas menos tratados por los interesados en la historia de la moda y la publicación permite reconstruirla, utilizando la revista como fuente secundaria de los contenidos del pasado y como recurso primario para el período de su publicación (1873-1880).

2) Fuente histórica:

Pese a ser una cabecera cuya vida transcurre en un momento político muy interesante, el último período del reinado de Amadeo de Saboya, la primera República y los primeros años de la Restauración, lo cierto es que carece de contenido político. No obstante, es una fuente histórica de gran interés porque incluye episodios de la historia de la peluquería en España y porque permite acercarse a un intento de crear un órgano que defienda los intereses del gremio de peluqueros y barberos. Esto hace que se pueda reconstruir un aspecto de la historia del asociacionismo en el país.

3) Localización de fondos

Todos los ejemplares pueden consultarse en la hemeroteca de la Biblioteca Nacional de España. 


\section{Estudio de la publicación}

La Guía comienza en su número uno con una declaración de intenciones, explicando las circunstancias de su origen. Así dice que llevan echando mucho tiempo en falta un periódico que defienda los intereses de su clase y que a la vez sea lazo de unión entre los peluqueros y barberos, permitiendo la circulación de noticias que les sean útiles a todos. Entre las cuestiones que espera resolver mencionan las de la contribución industrial (que quieren reunir firmas para solicitar a las Cortes su disminución, tras haberse multiplicado por cuatro) y las diferencias entre maestros y oficiales. También afirman no tener ánimo de lucro y dedicar el total de las suscripciones a la mejora de la publicación y a la formación de los profesionales. Por último, pretende dar a conocer la sociedad de Socorros Mutuos de peluqueros y barberos residentes en Madrid, que solo tiene dos años de existencia y va a cambiar en breve de junta directiva (Gascón pasará a ser su presidente), contribuyendo al asociacionismo del gremio en todo el país con el objetivo de buscar la mejora de la profesión. Igualmente piden colaboraciones de interés, sobre cuestiones históricas, prácticas o relacionadas con asuntos laborales, que no tardan en llegar e incluso en las páginas tienen lugar debates entre diferentes peluqueros de distintas provincias.

Pero aparte de esas cuestiones profesionales, llama la atención la extremada preocupación por la higiene y cómo intentan difundirla entre el gremio, convirtiéndose la revista en una desmitificadora de creencias populares. Así, en un artículo sobre la higiene de la cabeza, aseguran que es "es necesario atender con igual solicitud al cultivo de las facultades internas, que á la limpieza y aseo de la cubierta cutánea" ${ }^{9}$, acaban hablando de la limpieza en general, tratando la moda y el lavado del cuerpo. Y se lamentan de tener que rebajarse a tocar esos temas pues no están lo suficientemente extendidos, concluyendo que "parece ciertamente hasta depresivo para la sociedad el que un higienista descienda de su trípode científico armado de reglas que dictar á sus conciudadanos para la práctica de las abluciones, lavatorios y demás medios de refrescar y casi renovar la piel diariamente, porque el conocimiento de estos debia estar más generalizado y ser trasmitido de padres á hijos en la sucesión de las generaciones" ${ }^{10}$.

También insisten en diferenciar entre la higiene que tiene por "único y exclusivo objeto conservar la salud del individuo sustrayéndole al efecto á la influencia perniciosa" ${ }^{11}$ y la moda que a menudo consideran antihigiénica. Para comprenderlo ponen de ejemplo a los corsés "cuyo uso debiera estar proscrito por las leyes en todas las naciones, porque (...) Es, pues, antihigiénica en grado máximo la costumbre seguida por las mujeres de

\footnotetext{
9 “Higiene de la cabeza”, Guía del Peluquero y el Barbero, 16-01-1873, no2, p. 3.

10 “Higiene de la cabeza”, Guía del Peluquero y el Barbero, 16-02-1873, nํ4, pp. 3-4.

11 Ibídem
} 
todos los paises, de comprimir, só pretesto de hermosear el talle"12, en una avanzada reflexión que concluye abogando por sustituir el corsé por una banda de lienzo. Y sobre los sombreros también consideran que son insanos, afirmando que su peso "determina en la cabeza una traspiración abundante" ${ }^{13}$ que hace que el aire se enrarezca y, al mismo tiempo, calienta el cráneo provocando que, cuando al descubrirse entre aire frio, haya "funestas consecuencias" ${ }^{14}$. Para evitarlo proponen incorporar una rejilla de metal al sombrero.

E incluso en otros artículos que nada tienen que ver con el tema de la higiene se ven obligados a acabar con falsos mitos, recomendando el lavado escrupuloso. Así, a propósito de las causas de la calvicie, señalan que:

hay muchas personas que no se atreven á lavarse la cabeza por temor á la caída del cabello, ó por creer que al hacerlo así pueden estar predispuestos á padecer oftalmías, dolor de muelas, etc. Esta creencia es tan perjudicial á la belleza y al aseo, como la de que son víctimas algunas señoras que proscriben el agua para lavarse la cara y la sustituyen con pomadas destinadas á conservar la frescura de la tez. Esta creencia es un absurdo y debe rechazarse como tal. En efecto, los químicos de todas épocas están de acuerdo para reconocer que el agua es el gran disolvente de la naturaleza, y opinamos con ellos, que el agua pura es indispensable para el aseo de todas las partes del cuerpo para conservar la flexibilidad y frescura de la piel ${ }^{15}$.

Un tema que aparece reiteradamente son las diferencias biológicas entre razas y sus particularidades, en lo que parece un intento de ilustrar sobre aspectos de historia y geografía humanas a un gremio sin formación reglada. Entre los números uno y cinco aparece un artículo titulado "Varias clases de cabellos en las diferentes razas de hombres que pueblan el mundo", en el que dan cuenta de curiosidades relacionadas con la fisionomía y hacen afirmaciones que hoy resultan sin lugar a dudas racistas pero que en aquel momento estaban en la línea del pensamiento evolucionista y colonialista. Así dicen, por ejemplo, que hay en Laponia y en las costas septentrionales de la Tartaria "una casta de hombres de pequeña estatura y de figura extraña, tan rústicos en su fisonomía como en sus costumbres. Estos hombres, que parece han degenerado de la especie humana, no dejan de ser bastante numerosos ni de ocupar vastísimos territorios" ${ }^{16}$. En el número cuatro, a propósito de explicar las clases de cabello en las

\footnotetext{
12 Ibídem

13 “Higiene de la cabeza”, Guía del Peluquero y el Barbero, 1-02-1873, nำ, p. 3.

${ }^{14}$ Ibídem.

15 "De la calvicie. Causas que la producen y modo de evitarla en algunos casos", Guía del Peluquero y el Barbero, 16-07-1873, no14, pp. 2-3.

16 "Varias clases de cabellos en las diferentes razas de hombres que pueblan el mundo", Guía del Peluquero y el Barbero, 1-01-1873, nำ1, p. 2.
} 
generaciones mezcladas de europeos y americanos, afirman que "de europea y cuarterón, sale la especie octavona, la cual solo tiene una octava parte de sangre americana. Esta especie es de un color moreno claro, pero suficiente para hacerla distinguir con facilidad de los verdaderos hombres blancos de nuestros climas" ${ }^{17} \mathrm{y}$ aclaran que estos recibieron de Clemente XI una bula, en la que se les concedían los mismos privilegios que a los blancos y que su pelo es liso y negro, careciendo los varones de barba. El artículo concluye con una castiza referencia a que de la mezcla de "octavon y de negra sale, en fin, el verdadero negro con pasas" ${ }^{18}$.

También hay muchos textos relacionados con la historia de la peluquería, explicando el origen de la misma y su evolución a lo largo del tiempo. El objetivo de los mismos, aunque no está explicitado, es dar valor a la profesión y también fomentar la unión entre sus miembros, como se ve en estos párrafos:

La costumbre de cubrir la calvicie con cabellos postizos se remonta á la mayor antigüedad; pero durante muchos siglos se disimulaba este defecto de una manera muy incompleta (...) pero la invención de las pelucas puede asegurarse que no data más allá de principios del siglo XVII.

"Es indudable que la peluquería tuvo su origen en Francia. En 1636, Luis XIV creó 48 peluqueros-barberos con el objeto de que siguiesen su córte, y 200 para el servicio público. (...) Como se vé por estos datos, es indudable que los primeros peluqueros hacían también el oficio de barberos. Poco tiempo, después del nombramiento de los 248 peluqueros-barberos, parecióle á M. Colbert, célebre ministro de Luis XIV, qué salían de Francia sumas inmensas para comprar cabellos en las naciones vecinas, y á petición suya se resolvió que se aboliesen las pelucas (...) Así que comprendieron los peluqueros-barberos que se trataba de prohibirles la facultad de hacer pelucas, presentaron al consejo del rey una memoria acompañada de una tarifa, por la cual hacían ver, que siendo ellos los primeros que ejercían este nuevo arte, que todavía no habia pasado á los Estados vecinos, como España, Italia, Inglaterra, etc., sobrepujárian en mucho al gasto las remesas de pelucas que se exportarían para dichas naciones, y que por este medio volverían á Francia sumas mucho más considerables que las que saliesen para las compras de pelo.

"A principios del siglo XVIII ya se conocían algunos peluqueros en España, la mayor parte franceses, dedicados exclusivamente á la confección de postizos, corte, rizado y peinado de los cabellos dejando las atribuciones de afeitar á los cirujanos y barberos. En esta época, y durante todo el siglo XVIII, los peluqueros

17 "Genealogía de las generaciones mezcladas de europeos y americanos y sus diferentes clases de cabellos", Guía del Peluquero y el Barbero, 16-2-1873, nㅇ4, p.4.

18 Ibídem. 
eran muy instruidos, pues su arte tenia gran importancia; por lo que estaban muy bien retribuidos, lo cual les permitía dedicarse al estudio, principalmente de la historia y del dibujo ${ }^{19}$.

En relación con esto queremos mencionar que la cabecera contribuyó decididamente a difundir las tendencias francesas en el país. El afrancesamiento fue una consecuencia de la llegada de la dinastía de los Borbones en España tras la Guerra de Sucesión pero fue especialmente notable desde la Guerra de la Independencia cuando la nobleza y el resto de la sociedad despreciaron las tendencias nacionales y prefirieron emular las del país vecino. Sobre esto es especialmente importante que Domingo Gascón considera que es en Francia donde el gremio hispano debe mirar y por eso intenta establecer contactos a través de la revista, publicando diversos artículos de profesionales franceses. Sin embargo, es en las láminas iluminadas donde mejor se ve la influencia gala (y es en ellas en las que se deduce el objetivo de introducir y reforzar en España estas novedades). Estas imágenes, que son un poderoso reclamo, en general reproducen peinados de mujer con diferentes vistas y a veces también incluyen ejemplos de cordonería o de utensilios que han aparecido en el mercado. Hay que señalar además que las láminas aparecen descritas en la revista con mucho detalle.

Pero además de difundir las últimas tendencias de moda, el otro objetivo fundamental de la publicación es fomentar la cohesión entre los profesionales del gremio. Así incluyen numerosa información sobre la Sociedad de Socorros Mutuos para peluqueros y barberos de Madrid, dando cuenta del estado de la tesorería, de las reuniones que se celebran, de los cambios de estatutos y de las novedades en la junta directiva. También informan de fallecimientos de socios, hacen suscripciones ${ }^{20}$ para los heridos de diversas catástrofes (relacionadas o no con la profesión), dan noticia de huelgas y conflictos del gremio ${ }^{21}$ y reflexionan sobre la decadencia de la peluquería en España y el precio justo sobre los servicios prestados, que en la actualidad consideraban bajo. La unión de los trabajadores del gremio entiende que es la única forma en que puede progresar la profesión y orientan la mirada hacia Francia.

Un artículo muy interesante, que reflexiona sobre el asociacionismo, es el publicado en los números 82 y 83 en el que tratan sobre la realidad de las clases trabajadoras y sobre la cuestión social de las relaciones entre el capital y el trabajo. El texto está relacionado con unas conferencias del Ateneo de Madrid y en él abogan por la cooperación corporativa en todos los oficios porque lo consideran indispensable para la vida

\footnotetext{
19 "Historia de la peluquería desde su origen hasta nuestros días", Guía del Peluquero y el Barbero, 1-051873, nำ, pp. 1-2.

${ }^{20}$ Por ejemplo, en el número 30, de 16/03/1874, para el socorro de los heridos inutilizados del ejército de la nación en la actual guerra civil o en el 97, de 01/10/1879, a favor de las provincias de Murcia, Alicante y Almería, que habían sufrido inundaciones.

${ }^{21}$ Así, en el número 10 critican la huelga de oficiales de Sevilla, por ejemplo.
} 
económica. Por ello abogan por reproducir en España las Cámaras sindicales de los peluqueros franceses porque esas sociedades libres han conseguido establecer un vínculo entre maestros y oficiales, a diferencia de en nuestro país, en el que hay una guerra entre cada escalafón de la profesión. En consecuencia, en el resto de números, siguen dando información sobre el tema de la unión y el progreso. Y la revista misma sirve como medio de comunicación entre profesionales. En todos los números aparece una sección de correspondencia en la que los peluqueros dan cuenta de sus cuitas diarias y se comunican entre ellos, aparte de los artículos que remiten sobre sus opiniones.

Pero aparte de estas cuestiones relacionadas con el corporativismo, hay que mencionar que también la publicación tiene contenido recreativo y literario, siempre relacionado con la peluquería. Por ejemplo, incluye graciosos epigramas: "Dice la calva María / que es suyo propio el cabello; / y dice bien, que de balde / o se lo dá el peluquero" 22, poesías, fábulas, pequeñas composiciones e incluso en algunos números aparecen relatos (EI peluquero de Moscow, por el Vizconde de San Javier, que se puede leer entre el 40 y el 50). Por último, queremos hacer referencia a los anuncios que se incluyen en la cabecera, que dan cuenta de ofertas de trabajo, de ventas y oportunidades disponibles así como de peluqueros destacados. También aparecen reclamos para comprar objetos y libros relacionados con la profesión.

\section{Conclusiones}

En conclusión, podemos afirmar que la Guía del Peluquero es una excepción en la prensa de moda del siglo XIX por diferentes circunstancias. En primer lugar, está destinada al público masculino, una rareza ya que desde la Revolución Francesa la moda se consideró fundamentalmente un interés femenino, aunque también incluye tendencias para mujeres. Por otra parte, es un órgano de defensa de la clase obrera de los peluqueros y barberos y pretende ser un vehículo de instrucción, un nexo de unión y una herramienta con la que lograr el progreso de la profesión y con la que profundizar en el asociacionismo. La publicación se liga a la Sociedad de Socorros Mutuos de peluqueros y barberos de Madrid pero el fin último, perseguido por su ideólogo, fundador y propietario, es conseguir que en España se implanten las cámaras sindicales francesas que considera que son un gran avance para la mejora de su clase. Además la revista sirve de herramienta de comunicación entre las distintas provincias españolas y es un referente en el panorama internacional, vinculando el país con Francia, sobre todo.

\footnotetext{
22 “Epigrama”, Guía del Peluquero y el Barbero, 16-04-1873, nㅇ, p. 6.
} 
Así, la Guía es también un instrumento de propaganda del afrancesamiento en España, no solamente en lo referido a las novedades asociacionistas del país sino también de las tendencias y gustos. Como ya hemos mencionado, en el siglo XIX se asiste entre la clase alta nacional a un interés por las novedades galas, en detrimento de la cultura hispana que se considera poco sofisticada, antigua y sin futuro.

Además, consideramos que la larga vida de la cabecera (1873-1880) es prueba de su influencia y del interés que generó en la profesión. De hecho, sus páginas son testigos de debates y controversias de distintos maestros, oficiales y personalidades relacionadas con la peluquería que dan cuenta de sus cuitas, sus problemas y sus intereses. Un tema que preocupa en la revista son las suscripciones, auténtico quebradero de cabeza para las publicaciones decimonónicas, pues eran la herramienta que garantizaba la viabilidad del papel. En este caso se da cuenta de un nutrido grupo de fieles suscriptores de toda España, aunque finalmente la Guía termina su existencia por diversos motivos, entre ellos, los nuevos intereses de su fundador. Sin embargo, no es fácil deducirlos pues el número 108 termina sin referir que es el último de la publicación.

El legado de la revista en ese centenar largo de números es interesante porque permite conocer la historia de la peluquería en España, acercándonos a la visión que se tenía de la profesión desde dentro y en ese momento, pero también debido a que da cuenta de un intento de asociacionismo. Los estudios sobre la profesión de la peluquería y su devenir, así como de las modas en el peinado, no son muy numerosos y esta publicación sirve para reconstruir un aspecto de la historia de la moda y la belleza poco conocido pero con gran repercusión social.

Con este trabajo hemos pretendido cubrir un vacío historiográfico sobre las publicaciones de moda en España pero también acerca de la prensa de tipo mutualista. Su existencia habla de los cambios sociales habidos en el paso del reinado de Isabel II a la Restauración, época en que se inscribe la cabecera, y de cómo aumentó el nivel de vida, la alfabetización y también el interés de los trabajadores por organizarse. Y, pese a ello, hasta este ahora la revista no había suscitado interés entre los investigadores. Es por ello que concluimos este trabajo refiriéndonos a la necesidad de profundizar las investigaciones sobre prensa histórica. 


\section{Fuentes primarias utilizadas}

Colección completa (ejemplares 1 a 108) de la Guía del Peluquero (1873-1880).

\section{Referencias bibliográficas}

AMARA, L. (2014): Historia descabellada de la peluca, Anagrama.

ALMUIÑA FERNÁNDEZ, C. (1977): La Prensa Vallisoletana durante el siglo XIX (18081894), Valladolid, Diputación provincial de Valladolid.

BARADO, F. (1880): Historia del peinado, Barcelona, José Serra.

BORNAY, E. (1994): La cabellera femenina, Madrid, Cátedra.

BOTREL, J.F. (1993): Libros, prensa y lectura en la España del siglo XIX, Madrid, Fundación Germán Sánchez Ruipérez.

- (2003): Historia de la edición y de la lectura en España, 1472-1914, Madrid, Fundación Germán Sánchez Ruipérez.

CHECA GODOY, A. (2002): Historia de la prensa pedagógica en España, Sevilla, Universidad de Sevilla.

FLÜGEL, J.C. (2015): Psicología del vestido, Melusina.

GALLEGO, J. (1990): Mujeres de papel: de Hola! a Vogue: la prensa femenina en la actualidad, Icaria.

- (2013): De reinas a ciudadanas: Medios de comunicación, ¿motor o rémora para la igualdad?, España, Aresta Mujeres.

GARRIDO, M. (2012): Revistas femeninas de alta gama: Crónica de un desdén, Comunicación Social Ediciones y Publicaciones.

GARSAULT (1771): Arte de Barbero-Peluquero-Bañero..., Madrid, Imprenta de Andrés Ramírez.

GAY TAENGA, V. (1877): Manual instructivo para el barbero de pueblo, Valencia, Pascual Aguilar.

GOUGH-YATES, A. (2003): Understanding Women's Magazines, Routledge. 
HARTZENBUSCH, E. (1894): Apuntes para un catálogo de periódicos madrileños desde el año 1661 al 1870, Madrid, Estab. tip. Sucesores de Rivadeneyra.

ISISARRI, L. (1780): Memoria escrita por el presbitero D. Lorenzo de Isisarri, sobre peinadores sueltos de Madrid, 1780.

JIMÉNEZ, I. (1992): Prensa femenina en España (desde sus orígenes a 1868), Ediciones de la Torre.

LAVER, J. (2006): Breve historia del traje y la moda, Madrid, Cátedra.

MUÑOZ, C. (2002): Mujer mítica, mujeres reales: las revistas femeninas en España, 19551970, Universidad Complutense de Madrid.

NORRIS, P. (1997): Women, Media, and Politics, OUP USA.

PERINAT, A.; MARRADES, M. I. (1980): Mujer, prensa y sociedad en España, 1800-1939, CIS.

ROIG, M. (1977): La mujer y la prensa desde el siglo XVII a nuestros días, Madrid, La Torre.

- (1989): A través de la prensa: la mujer en la historia: Francia, Italia, España, S. XVIII-XX, Ministerio de Asuntos Sociales, Instituto de la Mujer.

SÁNCHEZ HERNÁNDEZ, M. (2009): “Evolución de las publicaciones femeninas en España: Localización y análisis", en Documentación de las ciencias de la información, no32, 2009, págs. 217-244

SIMÓN PALMER, M.C. (1975): "Revistas españolas femeninas del siglo XIX", en Homenaje a Don Agustín Millares Carlo, Confederación Española de Cajas de Ahorros, Las Palmas de Gran Canaria, pp. 401-446.

- (1991): Escritoras españolas del siglo XIX: manual bio-bibliográfico, Editorial Castalia.

- (1993): Revistas femeninas madrileñas, Madrid, Artes Gráficas Municipales.

-(2014): "La mirada social en la prensa: Concepción Arenal" en Arbor: Ciencia, pensamiento y cultura, no 767 (mayo-junio 2014), 2014.

VELASCO MOLPECERES, A.M (2016): Moda y prensa femenina en España (siglo XIX), Madrid, Ediciones 19.

VILLARET, M. (1832): Arte de peinarse las señoras a sí mismas y manual del peluquero, Madrid, Librería de Pérez.

VON BOEHN, M. (1928): Historia del traje en Europa desde los orígenes del cristianismo hasta nuestros días, Barcelona, Salvat. 
VV. AA. (1791): Ordenanzas del gremio de peluqueros, dadas por Carlos III, Madrid, Imprenta de Santos Alonso.

VV. AA. (1806): Ensayo de una historia de las pelucas por el Dr. Arkelio Rapsodia, Madrid, Imprenta de Collado.

VV. AA. (1869): Reglamento de la Sociedad de Socorros Mutuos, para los señores peluqueros y barberos avecindados en Madrid, Madrid, Imprenta del Colegio Nacional de Sordo-Mudos y de Ciegos.

WALKER, N. (1998): Women's Magazines, 1940-1960: Gender Roles and the Popular Press, Palgrave Macmillan US.

ZUCKERMANN, M.E. (1998): A History of Popular Women's Magazines in the United States, 1792-1995, Praeger. 